\title{
Article \\ Starch Morphology and Metabolomic Analyses Reveal That the Effect of High Temperature on Cooked Rice Elongation and Expansion Varied in Indica and Japonica Rice Cultivars
}

\author{
Nnaemeka Emmanuel Okpala 1,2,3 (D), Mouloumdema Pouwedeou Potcho 1,2,3, Muhammad Imran 1,2,3 (D), \\ Tianyue An ${ }^{4}$, Gegen Bao ${ }^{5}$, Longxin $\mathrm{He}^{1,2,3}$, Lin $\operatorname{Li}^{1}$ and Xiangru Tang $1,2,3, *$ (D)
}

1 State Key Laboratory for Conservation and Ultilisation of Subtropical Agricultural Bioresources, South China Agricultural University, Guangzhou 510642, China; elmka2001@yahoo.co.uk (N.E.O.); gilbertpotcho@yahoo.fr (M.P.P.); imran_m1303@yahoo.com (M.I.); helx@stu.scau.edu.cn (L.H.); lilinhainanu@163.com (L.L.)

2 Scientific Observing and Experimental Station of Crop Cultivation in South China, Ministry of Agriculture, Guangzhou 510642, China

3 Guangzhou Key Laboratory for Science and Technology of Aromatic Rice, Guangzhou 510642, China

4 School of Integrated Traditional Chinese and Western Medicine, Binzhou Medical University, Yantai 264003, China; antianyue2007@126.com

check for updates

Citation: Okpala, N.E.; Potcho, M.P.; Imran, M.; An, T.; Bao, G.; He, L.; Li, L.; Tang, X. Starch Morphology and Metabolomic Analyses Reveal That the Effect of High Temperature on Cooked Rice Elongation and Expansion Varied in Indica and Japonica Rice Cultivars. Agronomy 2021, 11, 2416. https://doi.org/ 10.3390/agronomy11122416

Academic Editors: Syed

Tahir Ata-Ul-Karim,

Saadatullah Malghani and Muhammad Ishaq Asif Rehmani

Received: 18 October 2021

Accepted: 25 November 2021

Published: 27 November 2021

Publisher's Note: MDPI stays neutral with regard to jurisdictional claims in published maps and institutional affiliations.

Copyright: (c) 2021 by the authors. Licensee MDPI, Basel, Switzerland. This article is an open access article distributed under the terms and conditions of the Creative Commons Attribution (CC BY) license (https:/ / creativecommons.org/licenses/by/ $4.0 /)$.
5 Guangzhou Key Laboratory for Research and Development of Crop Germplasm Resources, Zhongkai University of Agriculture and Engineering, Guangzhou 510225, China; baogegen@126.com

* Correspondence: tangxr@scau.edu.cn; Tel.: +86-136-6015-8245

\begin{abstract}
Rice (Oryza sativa L.) is mainly grouped into indica and japonica varieties. The aim of this study was to investigate the effect of temperature on cooked rice elongation, cooked rice expansion, and rice fragrance. This study was conducted in three growth temperature chambers with indica cultivar Basmati 385 (B385) and japonica cultivar Yunjingyou (YJY). Grains of B385 grown in lowtemperature regimes had the highest cooked rice elongation and expansion, whereas the grains of YJY grown in high-temperature regimes had the highest cooked rice elongation and expansion. Starch granules of B385 grown in low-temperature regimes were more compact and bigger, compared to grains grown in medium- and high-temperature regimes. Conversely, the starch granules of YJY grown in high-temperature regimes were more compact and bigger, compared to those grown in medium- and low-temperature regimes. Metabolomic analyses showed that temperature affected the rice metabolome and revealed that cyclohexanol could be responsible for the differences observed in cooked rice elongation and expansion percentage. However, in both B385 and YJY, grains from low-temperature regimes had the highest 2-AP content and the lowest expression levels of the badh2 gene. The findings of this study will be useful to rice breeders and producers.
\end{abstract}

Keywords: rice; temperature; cooked rice elongation; cooked rice expansion; rice fragrance; 2-acetyl1-pyrroline; badh2

\section{Introduction}

Rice (Oryza sativa L.) is mainly grouped into indica and japonica ecotypes or races. Indica and japonica rice have marked differences in plant architecture, as well as agronomic and physiological features [1-3].

Amylose content percentage is an important trait used in the determination of rice grain quality $[4,5]$. High-amylose rice cultivars cook dry with firm and separate grains, while low-amylose rice cultivars are tender, glossy, and cohesive after cooking [6-8]. Indica rice cultivars have been reported to have higher amylose content percentage compared to japonica rice cultivars [9]. Champagne et al. [10] reported a negative correlation between apparent amylose content and slickness in rice and a weak negative correlation between springiness and amylose content in rice. 
Umemoto et al. [11] reported differences amylopectin structure between indica and japonica rice cultivars and also noted that the starch from japonica rice had lower gelatinization temperature, compared to the starch from indica rice. Similarly, Kang et al. [12] noted that the viscogram values of cooked indica rice cultivars were higher than those of cooked japonica rice cultivars. Other differences noted by the authors included higher hardness exhibited by indica cultivars compared to japonica cultivars, as well as less compact and smaller starch granules in indica cultivars compared to compact and larger starch granules in japonica cultivars.

Indica rice cultivars have been reported to have lower nitrogen utilization efficiency for biomass accumulation and higher nitrogen utilization efficiency for grain yield, compared to japonica rice cultivars [13]. Ntanos et al. [14] reported differences in dry matter and nitrogen translocation in indica and japonica rice cultivars.

Chen et al. [15] cloned the S5 gene, a major locus for indicia-japonica hybrid sterility and wide compatibility, and discovered that the indica S5-i allele and japonica S5-j allele differed by two nucleotides. Mano et al. [16] reported differences in the chemical compositions of glyceroglycolipids and cerebroside in indica and japonica rice cultivars.

Metabolomics and proteomics studies have also shown differences in indica and japonica rice cultivars. Hu et al. [1] noted that indica and japonica rice cultivars have significant variation in the relative abundance of metabolites. Yang et al. [17] reported differences in the protein composition of indica and japonica rice varieties.

However, the improvement of rice grain quality is one of the major challenges facing both indica and japonica rice breeders and producers. In other to improve rice grain quality, it is important to grasp the factors that influence the traits used in determining rice grain quality. Cooked rice elongation, cooked rice expansion [18], and rice fragrance [19] are some the major traits used in determining rice grain quality.

The genetic basis of cooked rice elongation and cooked rice expansion has not been fully elucidated. However, Arikit et al. [20] reported that the QTLs associated with cooked rice elongation were found near the locations of starch-biosynthesizing genes on chromosome 4 and chromosome 6 . Ge et al. [21] found that the QTL on chromosome 6 located near the waxy gene region was associated with cooked rice elongation and cooked rice expansion. Qiu et al. [22] reported slight genetic overlap between rice grain appearance quality and cooked rice elongation, and they stated that, among 60 appearance/quality QTLs and 14 cooked rice elongation QTLs, only two regions located on chromosome 5 and chromosome 6 showed pleiotropic effects on both appearance quality and cooked rice elongation. Ahn et al. [23] noted that a segment of rice chromosome 8, introgressed from rice cultivar Basmati 370, contains a gene or genes affecting grain elongation.

Rice fragrance is another important trait used in determining rice grain quality. Over 100 compounds have been associated with fragrance in rice [24,25], but the roles, genetics, and biosynthesis of these compounds are not yet well understood. Buttery et al. [26] reported that all fragrant rice varieties contain 2-acetyl-1-pyrroline (2-AP). Reports by Hinge et al. [27], Hashemi et al. [28],Bourgis et al. [29], Huang et al. [30], and Lorieux et al. [31] have also shown that 2-AP is responsible for fragrance in rice.

A single recessive gene, $f g r$, found on chromosome 8 of rice is associated with rice fragrance $[29,32,33]$ and determines the quantity of $2-\mathrm{AP}$ in rice $[28,32]$. Fine mapping of the $f g r$ locus on chromosome 8 of rice and extensive sequence analysis have identified two isozymes, BADH1 and BADH2, encoding BADH [34]. According to Bradbury et al. [35], $\mathrm{BADH} 1$ and $\mathrm{BADH} 2$ found in rice are encoded on chromosome 4and chromosome 8, respectively; however, only BADH2 is responsible for fragrance in rice. Badh2 is a dominant allele that encodes the BADH2 gene, while its nonfunctional recessive allele badh2 is responsible for fragrance in rice [34-36]. It has been shown that badh2 expression was negatively associated with 2-AP accumulation in fragrant rice [27].

Rice is the world's most important food crop [37] and the staple food of over half of the world's population [1]. The importance of rice is not limited to its nutritional value and economic importance. For researchers, rice is a valuable model system for 
cereal plant genetics, due to its sequenced and annotated genome [38] and its capacity for transformation, as well asits similarity to other major cereal crop species [39].

Therefore, it is very important that we understand the effects of temperature on rice grain quality. Perkins et al. [40] reported increases in warm spells and heat wave frequency at a global scale from 1950 to 2011. Russo et al. [41] predicted more heat waves in the coming years.

The high temperature associated with heat waves will have an impact on rice production. Yin et al. [42] reported that, when diurnal temperature delayed flowering in rice, it also increased the number of leaves. Exposure to high temperature above $50{ }^{\circ} \mathrm{C}$ for over $12 \mathrm{~h}$ has been shown to cause color degradation in freshly harvested rice grains [43]. Temperature can affect germination, growth, tiller number, heading time, and yield [44]. High temperature has also been reported to induce high disease incidence in rice compared to low temperature [45]. Temperature in rice has also been shown to affect the total plant biomass $[46,47]$. The aim of this study was to determine the effect of temperature on the cooked rice elongation, cooked rice expansion, and rice fragrance in indica and japonica rice cultivars.

\section{Materials and Methods}

\subsection{Rice Materials}

Plant materials were identified and provided by Professor Xiangru Tang. We did not deposit a voucher specimen of the rice cultivars in any public herbarium, but they can be provided upon request.

Basmati 385 (B385), a fragrant indica rice cultivar, and Yunjingyou (YJY), a fragrant japonica rice cultivar, were used for this study. Both cultivars were obtained from the College of Agriculture, South China Agricultural University, Guangzhou, China. They were sown in the early planting season. Seeds were soaked in water, before sowing them under greenhouse conditions following randomized blocks. A total of 36 plastic pots (18 pots for each cultivar) $-28 \mathrm{~cm}$ in height and $30 \mathrm{~cm}$ in diameter-already containing soil and $3 \mathrm{~g}$ of fragrant fertilizer $\left(15 \% \mathrm{~N}, 4 \% \mathrm{P}_{2} \mathrm{O}_{5}, 7 \% \mathrm{~K}_{2} \mathrm{O}, 25 \%\right.$ organic matter, and $2 \%$ $\mathrm{ZnCl}_{2}$ ), were used for this experiment. Five seedlings were transplanted to each plastic pot, and, for each cultivar, six pots were used per treatment. Then, 21 days after transplanting, another $2 \mathrm{~g}$ of fragrant rice fertilizer was added to each pot. At the onset of heading, the pots were transferred to three Conviron temperature-controlled chambers (manufactured by Controlled Environments Limited). The chambers were designated growth temperature one (GT1), growth temperature two (GT2), and growth temperature three (GT3). GT1 had its temperature set at $32{ }^{\circ} \mathrm{C}$ from 6:00 a.m. to 5:59 p.m. and $26{ }^{\circ} \mathrm{C}$ from 6:00 p.m. to 5:59 a.m., relative humidity was set at $80 \% \mathrm{RH}$, fluorescence was set at $450 \mu \mathrm{mol}$ from 6:00 a.m. to 10:59 a.m., $700 \mu \mathrm{mol}$ from 11:00 a.m. to 2:59 p.m., $450 \mu \mathrm{mol}$ from 3:00 p.m. to 5:59 p.m., and $0 \mu \mathrm{mol}$ from 6:00 p.m. to 5:59 a.m., and $\mathrm{CO}_{2}$ was set to $340 \mathrm{ppm}$. GT2 had its temperature set at $27^{\circ} \mathrm{C}$ from 6:00 a.m. to 5:59 p.m. and $21^{\circ} \mathrm{C}$ from 6:00 p.m. to 5:59 a.m. Relative humidity, fluorescence, and $\mathrm{CO}_{2}$ were the same as GT1. GT3 had its temperature set at $22{ }^{\circ} \mathrm{C}$ from 6:00 a.m. to 5:59 p.m. and $16^{\circ} \mathrm{C}$ from 6:00 p.m. to 5:59 a.m. Relative humidity, fluorescence, and $\mathrm{CO}_{2}$ were also the same as in GT1. All pots were uniformly watered during plant growth and development.

\subsection{Sample Collection}

At maturity, grain samples were collected and transferred to labeled plastic bags, where they were immediately frozen in liquid nitrogen, before transferring them to the laboratory for storage at $-80{ }^{\circ} \mathrm{C}$ pending further analysis. However, grains for cooked rice elongation and cooked rice expansion were dried at room temperature, as well as stored at room temperature, pending experiments. 


\subsection{Cooked Rice Elongation and Cooked Rice Expansion Percentage}

Cooked rice elongation was here represented as the difference between the length of grains measured before and after cooking. In this kind of investigation, precision is very crucial; therefore, a Microtek ScanMaker i 800 plus scanner was used to conduct all length measurements. One the other hand, cooked rice expansion was here represented as the difference between the perimeter of grains measured before and after cooking. After 6 months of storage, rice grains were used for the determination of cooked rice elongation and cooked rice expansion. The grains were milled with a JNMJ6 milling machine manufactured by Taizhou Grain Instrument Factory.

For each replicate, 10 milled rice grains were measured, using a Microtek ScanMaker i800 plus scanner. Each grain was then transferred to a PCR tube containing $150 \mu \mathrm{L}$ of distilled water. The PCR plate containing the rice grains was then placed in a PCR thermocycler, and the rice grains were individually cooked for $30 \mathrm{~min}$ at $99^{\circ} \mathrm{C}$ block temperature. The cooked rice grains were then removed from the PCR plate and placed on a filter paper. After drying for $5 \mathrm{~min}$ at room temperature, they were remeasured. As with the raw grains, 10 cooked grains were remeasured simultaneously; this helped to control the variability of water content that could have resulted from unequal resting times between measurements. These experiments were conducted with 10 grains per treatment and each treatment had three replicates.

In other to determine the elongation percentage of cooked rice for each treatment, the following formula was used [15]:

$$
\% \mathrm{E}=(\mathrm{ACML}-\mathrm{BCML}) / \mathrm{BCML} \times 100,
$$

where $\% \mathrm{E}$ is the elongation percentage, $\mathrm{ACML}$ is the mean length after cooking, and BCML is the mean length before cooking.

In other to determine the expansion percentage of cooked rice for each treatment, the following formula was used:

$$
\% \operatorname{Exp}=(\mathrm{ACMP}-\mathrm{BCMP}) / \mathrm{BCMP} \times 100,
$$

where $\%$ Exp is the elongation percentage, $\mathrm{ACMP}$ is the mean perimeter after cooking, and $\mathrm{BCMP}$ is the mean perimeter before cooking.

\subsection{Scanning Electron Microscopy}

Scanning electron microscopy was conducted using a Zeiss Scan Electron Microscope (EVOMA15). Rice grains sputter-coated with platinum were cut with a scalpel and examined at a magnification of $5000 \times$ at $5.00 \mathrm{kV}$.

In other to see the arrangement of the starch granules and the air spaces, starch granules were compared in their natural forms.

\subsection{RNA Extraction}

RNA extraction was carried out using a HiPure Plant RNA Mini Kit with the samples that were stored at $-80^{\circ} \mathrm{C}$. The protocol used for RNA extraction was based on the kit's manual.

\section{6. cDNA Synthesis and Quantitative Real-Time PCR ( $q R T-P C R$ )}

cDNA synthesis was performed according to the protocol stipulated Vazyme kit for HiScript II Q RT SuperMix for qPCR (+gDNA wiper). Analysis was performed with Biometra Tone 96 G. cDNA, when not used immediately, wasstored at $-80^{\circ} \mathrm{C}$.

qRT-PCR was carried out with SYBR qPCR Master Mix with Vazyme code Q311-02 5 mL 500 rxn.A BIO-RAD CFx96 Thermal Cycler was used for analysis. For each cultivar, qRT-PCR was performed with threereplicates of cDNA, and, according to Bao et al. [48], gene-specific primers (forward: 5'-GGTTGGTCTTCCTTCAGGTGTGC-3', reverse: 5'-CATCAACATCATCA TCAAACACCACTAT-3') were used. 


\subsection{GC-MS Analysis}

GC-MS analysis was carried out using a GCMS-QP2010 with samples that were stored at $-80^{\circ} \mathrm{C}$ immediately after collection from the temperature chambers. Every sample used in this study had three replicates. Each replicate was prepared with $1 \mathrm{~g}$ of grain sample that waspulverized to fine powder using alaboratory mortar and pestle.

The ground sample was transferred to a $20 \mathrm{~mL}$ bottle, followed by the addition of $10 \mathrm{~mL}$ of dichloromethane $\left(\mathrm{CH}_{2} \mathrm{CL}_{2}\right)$. Samples were then transferred to ultrasonic cleanser (KQ-800ES), set at $0{ }^{\circ} \mathrm{C}$ for $4 \mathrm{~h}$. Afterward, samples were allowed to cool for $60 \mathrm{~s}$ and then transferred to a $10 \mathrm{~mL}$ conical flask before the addition of $4 \mathrm{~g}$ of anhydrous sodium sulfite $\left(\mathrm{Na}_{2} \mathrm{SO}_{2}\right)$. After $30 \mathrm{~s}, 1 \mathrm{~mL}$ of the supernatant was transferred to a vial using asealed micropipette. This was followed by the addition of $2 \mu \mathrm{L}$ of 2,3,6-trimethylpyridine (1000× dilution with $\mathrm{CH}_{2} \mathrm{Cl}_{2}$ ) as an internal standard. Vials were closed and transferred to the GC-MS machine for analysis.

\subsection{Matured Rice Grain Length and Perimeter}

In other to determine the length and perimeter of rice grains, mature rice grains were scanned using a Microtek ScanMaker i800 plus scanner. This experiment was carried in threereplicates for each treatment. For each replicate, 20 grains of dehusked rice were scanned, and the average length and perimeter weredetermined. The rice grains used in this experiment were not milled to avoid differences that could occur during milling.

\subsection{Statistical Analysis}

Standardized metabolic data were used to perform principal component analysis (PCA). PCA was performed using SIMCA 14.1. The graphics of the heatmap was performed with TBtools software (version no 1.09852), and data values are presented on a log scale. To assess statistical differences among GT1, GT2, and GT3 regimes, Student's $t$-tests (performed using SPSS software) were conducted, with $p<0.05$ used as the criterion of significance. Different lowercase letters (in the figures) indicate significant differences among the mean values.

\section{Results}

\subsection{Cooked Rice Elongation and Cooked Rice Expansion Percentage}

The results of the cooked rice elongation and cooked rice expansion percentage show that, in indica and japonica cultivars, temperature affected both cultivars differently.

In B385, the cooked rice elongation percentage was $24 \%, 34 \%$, and $45 \%$ for the GT1, GT2, and GT3 regimes, respectively (Figure 1a). The cooked rice expansion percentage of B385 was 26\%, $48 \%$, and 58\% for the GT1, GT2, and GT3 regimes, respectively (Figure 1c). This result shows that GT3 (low-temperature regime) recorded the highest percentage of cooked rice elongation and expansion percentage in B385. The results of Student's $t$-tests showed significant differences $(p \leq 0.05)$ in the cooked rice elongation and cooked rice expansion percentages among the three growth temperature regimes.

In YJY, the cooked rice elongation percentage was $65 \%, 52 \%$, and $46 \%$ for the GT1, GT2, and GT3 regimes, respectively (Figure 1b). The cooked rice expansion percentage of YJY was $65 \%, 56 \%$, and $46 \%$ for the GT1, GT2, and GT3 regimes, respectively (Figure 1d). According to the results, in YJY, GT1 (high-temperature regime) recorded the highest cooked rice elongation and cooked rice expansion percentage. The results of Student's $t$-tests showed significant differences $(p \leq 0.05)$ in the cooked rice elongation and cooked rice expansion percentages among the three growth temperature regimes. 

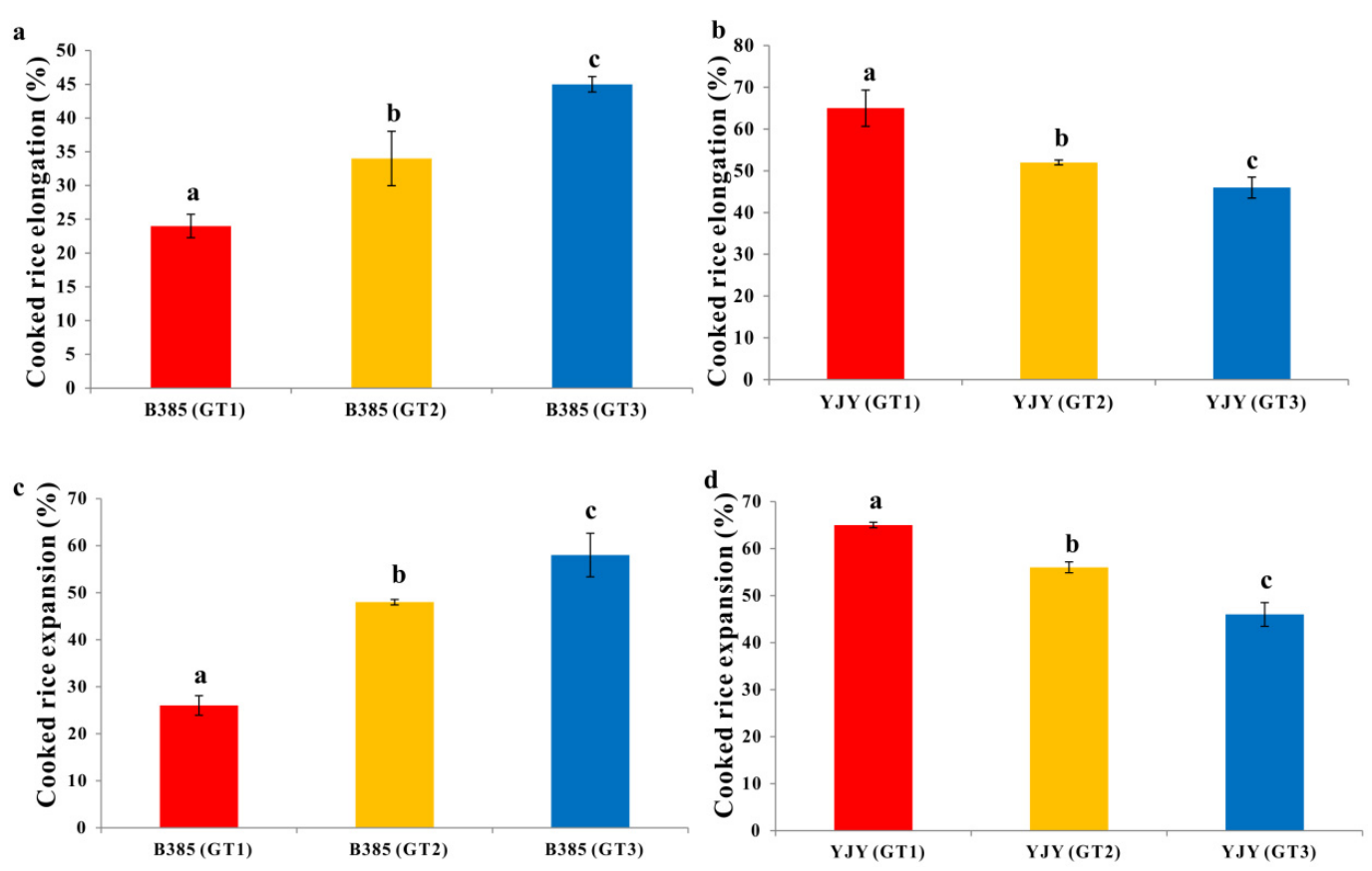

Figure 1. Cooked rice elongation percentage and cooked rice expansion percentage: (a) B385 cooked rice elongation percentage; (b) YJY cooked rice elongation percentage; (c) B385 cooked rice expansion percentage; (d) YJY cooked rice expansion percentage. Different lowercase letters indicate significant differences $(p<0.05)$ among the mean values.

\subsection{Starch Granule Morphology}

The images of the starch granule morphology of B385, as revealed in Figure 2a-c, showed compact and bigger starch granules in GT3 (low-temperature regime); however, the starch granules were less compact and smaller in the GT1 and GT2 regimes.
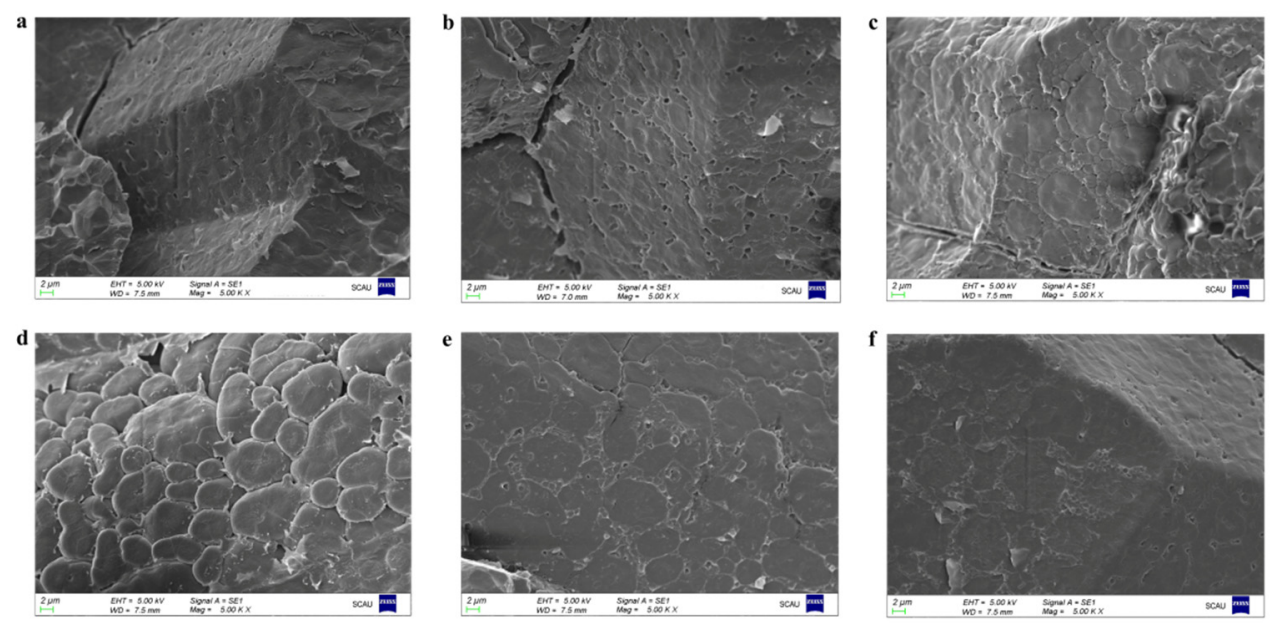

Figure 2. Starch granule morphology: (a) starch granule morphology of B385 grown in GT1 regime; (b) starch granule morphology of B385 grown in GT2 regime; (c) starch granule morphology of B385 grown in GT3 regime; (d) starch granule morphology of YJY grown in GT1 regime; (e) starch granule morphology of YJY grown in GT2 regime; (f) starch granule morphology of YJY grown in GT3 regime.

However, the images of the starch granule morphology of YJY, as revealed in Figure 2d-f, showed compact and bigger starch granules in GT1 (high-temperature regime); however, the starch granules were less compact and smaller in the GT2 and GT3 regimes. Generally, YJY had more compact and bigger starch granules, compared to B385. 


\subsection{Principal Component Analysis (PCA) and Heatmap}

The PCA results showed 95\% cumulative variance in the grains of B385 and YJY, with a score plot of PC1 versus PC2 explaining 0.35 and 0.232 variation, respectively (Figure 3).

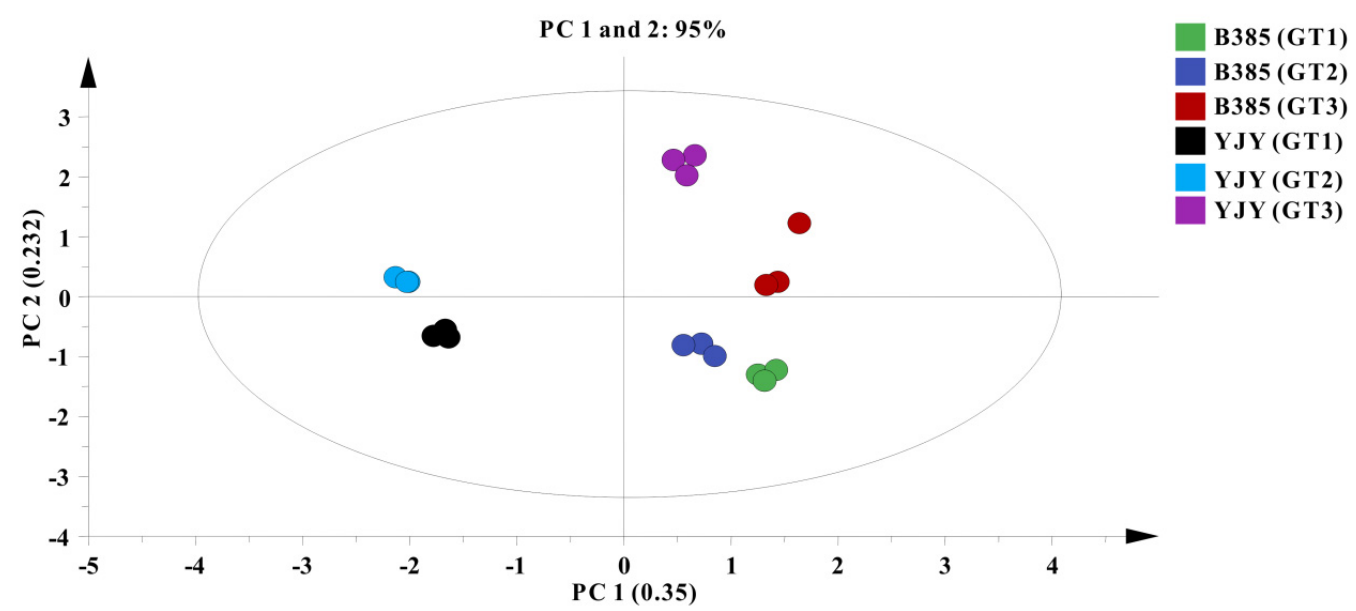

Figure 3. Principal component analysis of B385 and YJY grown in GT1, GT2, and GT3 regimes.

The heatmap showed that the highest abundance of cyclohexanol in B385 was recorded in GT3 (low-temperature regime); conversely, in YJY, cyclohexanol recorded its highest abundance in GT1 (high-temperature regime). The abundance of cyclohexanol in the grains correlated with cooked rice elongation and cooked rice expansion percentage. The abundance of cyclohexanol in the heat map is highlighted in green (Figure $4 a, b)$. The results of Student's $t$-tests showed significant differences $(p \leq 0.05)$ in cyclohexanol in B385 among the three growth temperature regimes (Figure 4c), as well as in YJY among the three growth temperature regimes (Figure 4d).

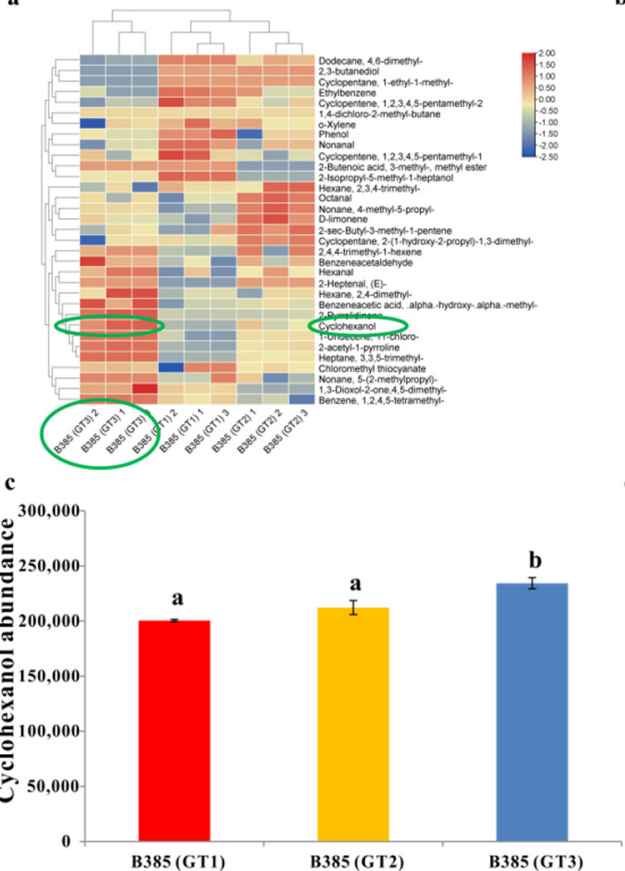

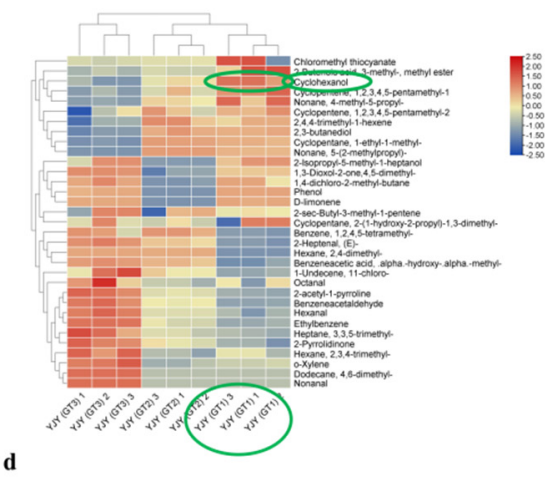

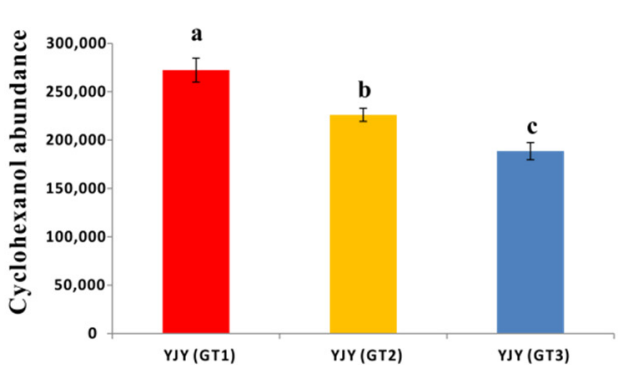

Figure 4. Heatmaps and cyclohexanol abundance: (a) heatmap of compounds identified in B385 grown in GT1, GT2, and GT3 regimes; (b) heatmap of compounds identified in YJY grown in GT1, GT2, and GT3 regimes; (c) cyclohexanol abundance in B385; (d) cyclohexanol abundance in YJY. Different lowercase letters indicate significant differences $(p<0.05)$ among the mean values. 


\subsection{Unmilled Rice Grain Length and Parameter}

Unlike the results of the cooked rice elongation and cooked rice expansion, the results of unmilled grain length and perimeter showed that temperature affected both cultivars in a similar fashion (Figure 5).
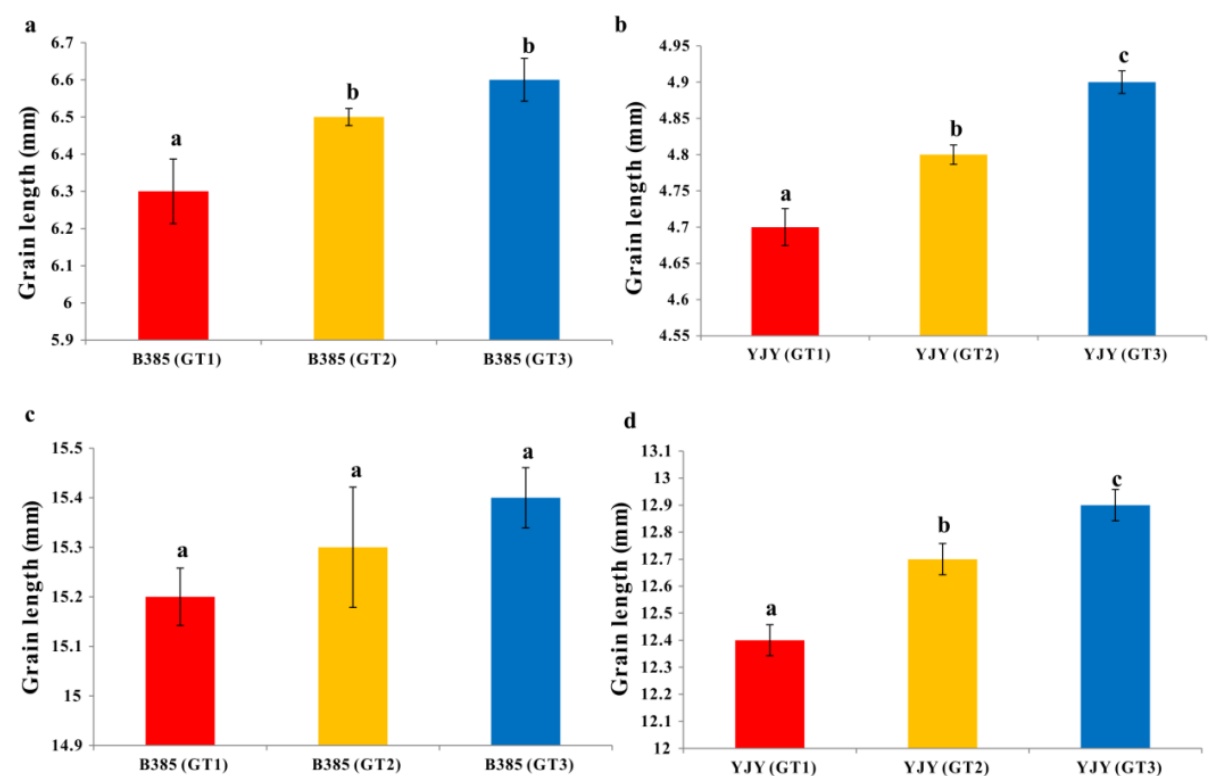

Figure 5. Unmilled rice grain length and perimeter: (a) grain length of B385; (b) grain length of YJY; (c) grain perimeter of B385; (d) grain perimeter of YJY. Different lowercase letters indicate significant differences $(p<0.05)$ among the mean values.

The rice grain length of B385 was $6.3 \mathrm{~mm}, 6.5 \mathrm{~mm}$, and $6.6 \mathrm{~mm}$ for the GT1, GT2, and GT3 regimes, respectively. The grain perimeter of B385 was $15.2 \mathrm{~mm}, 15.3 \mathrm{~mm}$, and $15.4 \mathrm{~mm}$ for the GT1, GT2, and GT3 regimes, respectively.

In YJY, the grain length was $4.7 \mathrm{~mm}, 4.8 \mathrm{~mm}$, and $4.9 \mathrm{~mm}$ for the GT1, GT2, and GT3 regimes, respectively. The grain perimeter of YJY was $12.4 \mathrm{~mm}, 12.7 \mathrm{~mm}$, and $12.9 \mathrm{~mm}$ for the GT1, GT2, and GT3 regimes, respectively.

The results of Student's $t$-tests showed significant differences $(p \leq 0.05)$ in the grain length and perimeter of YJY; however, in B385, only the length in GT1 was significantly different, whereas the perimeter results did not show a significant difference.

\subsection{2-AP Content and badh2 Gene Expression Levels}

The result of 2-AP in the grains of B385 and YJY showed that 2-AP content increased with a decrease in temperature, whereas the results of badh2 expression levels revealed a negative correlation of badh2 with high 2-AP content (Figure 6).

In B385, 2-AP content was $7930 \mu \mathrm{g} / \mathrm{kg}, 12,730 \mu \mathrm{g} / \mathrm{kg}$, and 20,652 $\mu \mathrm{g} / \mathrm{kg}$ in the GT1, GT2, and GT3 regimes, respectively. However, the badh2 expression levels in the grains of B385 were 1, 0.6, and 0.4 for the GT1, GT2, and GT3 regimes, respectively. Student's $t$-tests showed significant differences $(p \leq 0.05)$ in 2-AP content among the three growth temperature regimes. Similarly, there were significant differences in the badh 2 expression levels among the three growth temperature regimes.

The 2-AP content in the grains of YJY was $8589 \mu \mathrm{g} / \mathrm{kg}$, $9746 \mu \mathrm{g} / \mathrm{kg}$, and 12,550 $\mu \mathrm{g} / \mathrm{kg}$ for the GT1, GT2, and GT3 regimes, respectively. However, the badh2 expression levels in the grains of YJY were 1.4, 1.1, and 0.6 for the GT1, GT2, and GT3 regimes, respectively. Student's $t$-tests showed significant differences $(p \leq 0.05)$ in the 2-AP content among the three growth temperature regimes. Similarly, there were significant differences in the badh 2 expression levels among the three growth temperature regimes. 

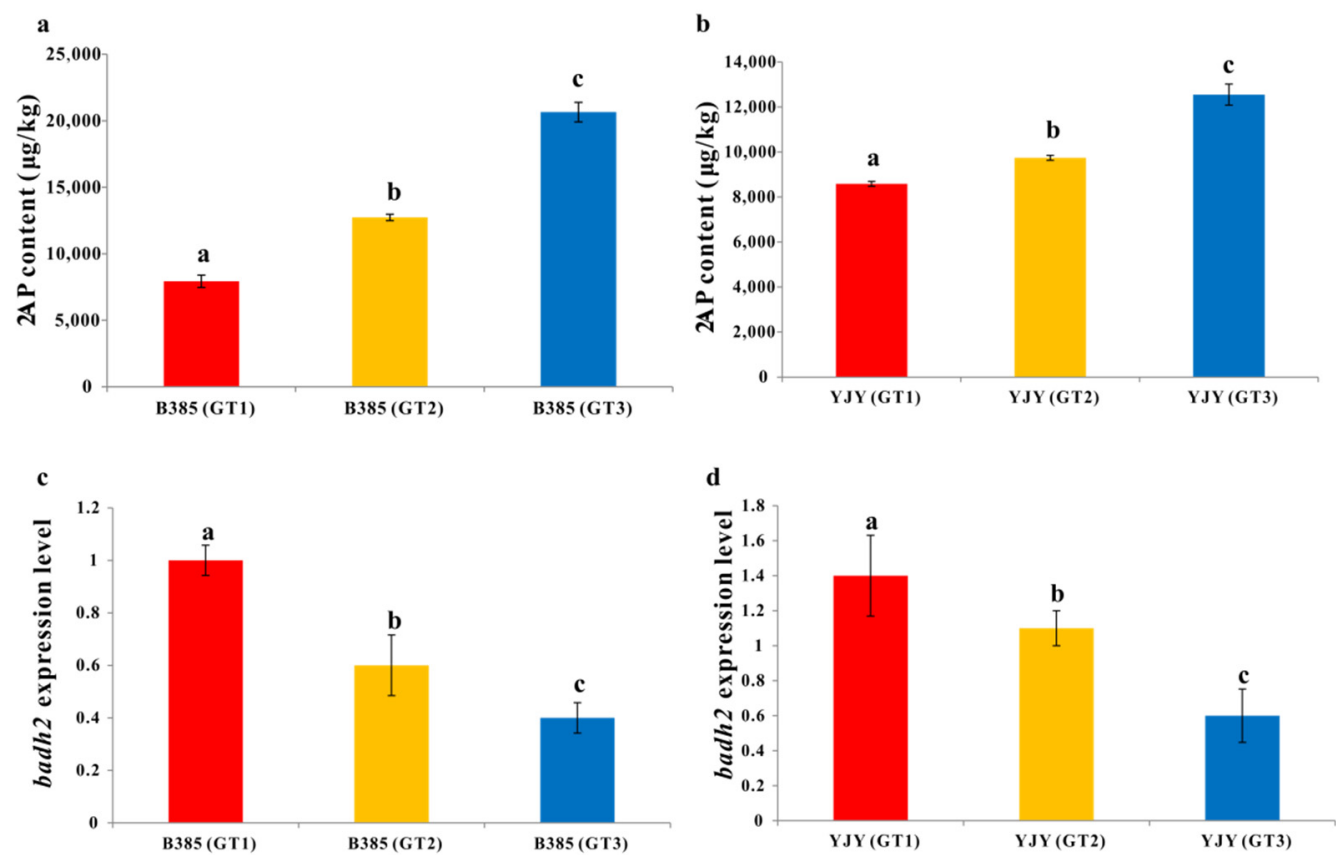

Figure 6. 2-AP content and badh2 gene expression levels: (a) 2-AP content in B385; (b) 2-AP content in YJY; (c) badh2 expression levels in B385; (d) badh2 expression levels in YJY. Different lowercase letters indicate significant differences $(p<0.05)$ among the mean values.

\section{Discussion}

In the past several decades, heat wave frequency has been on the rise [40], and the trend is expected to continue in the coming years [41]. In the present study, we investigated how three different growth temperature regimes affected cooked rice elongation and expansion percentage in indica and japonica rice cultivars. Cooked rice elongation and cooked expansion are important traits that are used in assessing rice grain quality.

The findings of this study showed that the effects of growth temperature on cooked rice elongation and expansion were different in B385 and YJY. Our results, as shown in Figure 1, revealed that B385 recorded the highest cooked rice elongation percentage and cooked rice expansion percentage in GT3 (low-temperature regime) and the lowest cooked rice elongation percentage and cooked rice expansion percentage in GT1 (hightemperature regime). Conversely, in YJY, the highest cooked rice elongation percentage and cooked rice expansion percentage were recorded in GT1 (high-temperature regime), and the lowest cooked rice elongation percentage and cooked rice expansion percentage were recorded in GT3 (low-temperature regime). B385 is an indica cultivar, whereas YJY is a japonica cultivar. Rice starch properties have been shown to be correlated with cooked rice elongation. Arikit et al. [20] identified three QTLs for cooked rice elongation-two on chromosome 6 and one on chromosome 4-and observed that all three QTLs were located near starch-biosynthesizing genes. In this study, we reported a correlation between starch granule morphology and cooked rice elongation percentage.

In other to observe the arrangement of starch granules and the air spaces, we analyzed the starch granules in their natural forms. Kang et al. [12] reported less compact and smaller starch granules in indica cultivars, compared to more compact and larger starch granules in japonica cultivars. In the present study, as shown in Figure 2, we also generally observed less compact and smaller starch granules in B385 and more compact and larger starch granules in YJY.

However, we also observed that B385 grown in the GT3 regime had the most compact and largest starch granules among B385 cultivars from the three growth temperature regimes, whereas B385 grown in the GT1 regime had the least compact and smallest starch granules among B385 cultivars from the three growth temperature regimes. Conversely, YJY grown in the GT1 regime had the most compact and largest starch granules, whereas 
YJY grown in GT3 regime had the least compact and smallest starch granules among YJY cultivars from the three growth temperature regimes. Reports have shown that starch is correlated with cooked rice elongation and cooked rice expansion $[18,20,21]$. The waxy gene region is associated with starch biosynthesis in rice [49] and has been shown to be temperature-sensitive [50,51]. The waxy gene is located on chromosome 6 of rice and consists of 14 exons and 13 introns [52].Two alleles of the waxy gene, $w^{2} y^{\mathrm{a}}$ and waxy $^{\mathrm{b}}$, are widely distributed in rice. The $w a x y^{\mathrm{a}}$ allele is widely distributed in indica rice varieties, whereas the waxy $y^{b}$ allele is widely distributed in japonica rice varieties $[53,54]$. The QTL on chromosome 6 located near the waxy gene region has been associated with cooked rice elongation and cooked rice expansion [21]. Therefore, the differences that we reported in starch granule morphology could explain why B385 grown in the GT3 regime had the highest cooked rice elongation and cooked rice expansion percentage among B385 cultivars, whereas YJY grown in the GT1 regime had the highest cooked rice elongation and cooked rice expansion percentage among YJY cultivars. Tang et al. [55] also showed that temperature affected starch properties and rice grain quality. Huang et al. [56] showed that changes in temperature affected the appearance, gel consistency, gelatinization temperature, and protein content of rice. Temperature has also been shown to affect the yield [44] and amylose content of rice [5].

In other to determine if chemical compounds also played some roles in the differences observed in cooked rice elongation and cooked rice expansion in B385 and YJY, we carried out further analyses. The PCA result in Figure 3 showed that growth temperature affected the metabolome of both B385 and YJY. From the PCA result, we observed that, in each cultivar, the three replicates grown in the same temperature regime were clustered together. This result shows that growth temperature had profound effect on the grain and suggests that the differences observed in cooked rice elongation and cooked rice expansion were as a result of differences in growth temperature.

In addition to PCA, we carried out heatmap analysis (Figure 4), which revealed that, in B385, cyclohexanol had its highest abundance in grains grown in the GT3 regime, whereas, in YJY, cyclohexanol had its highest abundance in grains grown in the GT1 regime. The correlation between cyclohexanol and cooked rice elongation and expansion percentage suggests that cyclohexanol likely plays some roles in cooked rice elongation and cooked rice expansion. It is unclear why, in B385, cyclohexanol had its highest abundance in the GT3 regime, whereas, in YJY, it had its highest abundance in the GT1 regime. The possible explanation for this could be that the metabolites reacted differently with cyclohexanol in B385 compared to YJY. According to Hu et al. [1], there is significant variation in the relative abundance of metabolites in indica and japonica rice cultivars.

In Figure 5 we showed the results of unmilled grain length and perimeter. The results showed that, in both B385 and YJY, grains that were harvested from the GT3 regime had the longest length and largest perimeter, whereas the grains that were harvested from the GT1 regime had the shortest length and smallest perimeter. Our results also showed that, in both B385 and YJY, the differences in unmilled grain length and perimeter (Figure 5) between rice grains harvested in the three growth temperature regimes were much smaller, compared to the differences in cooked rice elongation and cooked rice expansion (Figure 1). On the basis of these results, we can speculate that the mechanism of grain elongation and expansion during rice growth and development differs from the mechanism of cooked rice elongation and cooked rice expansion.

Lastly, we also investigated the effect of temperature on 2-AP, the major compound associated with fragrance in rice. Our results showed that, in both B385 and YJY, grains harvested from rice plants grown in GT3 had the highest content of 2-AP, whereas grains harvested from rice plants grown in GT1 had the lowest content of 2-AP (Figure 6a,b).The badh2 gene is responsible for fragrance in rice [34-36,57]. We also discovered that, in both B385 and YJY, grains harvested from rice plants grown in the GT3 regime had the lowest expression of $b a d h 2$, whereas grains harvested from rice plants grown in the GT1 regime had the highest expression levels of badh 2 (Figure $6 c, d$ ). These findings are in agreement 
with Hinge et al. [27] who reported that a negative expression of badh2 is associated with the biosynthesis of 2-AP in fragrant rice. Our results showed that low temperature increased the biosynthesis of 2-AP in both indica and japonica rice cultivars.

The findings of this study revealed that the effect of growth temperature on cooked rice elongation and cooked rice expansion varies in indica and japonica rice cultivars. Since cooked rice elongation and cooked rice expansion are important traits used in determining rice grain quality, more studies should be carried out to understand the genetic basis of the difference. Our results also suggest that the mechanism of rice grain elongation and expansion differs from the mechanism of cooked rice elongation and cooked rice expansion. Lastly, we showed that low temperature increased the biosynthesis of 2-AP in both indica and japonica rice cultivars. The popularity of Basmati rice around the globe is due to its fragrance and extensive elongation after cooking. This study showed that high temperature is detrimental to both traits that make Basmati rice popular. It has been predicted that heat wave frequency will increase in the coming years; therefore, it is important for rice breeders to understand the effect of temperature on rice quality, so as to develop new cultivars with better grain quality.

Author Contributions: Conceptualization, X.T. and N.E.O.; methodology, X.T. and N.E.O.; software, N.E.O., M.P.P., M.I., T.A. and G.B.; validation, X.T. and N.E.O.; formal analysis, N.E.O. and M.P.P.; investigation, N.E.O., M.P.P., G.B., L.L. and L.H.; data curation, N.E.O., M.P.P. and T.A.; writingoriginal draft preparation, N.E.O.; writing-review and editing, N.E.O.; visualization, X.T. and N.E.O.; project administration, X.T. and N.E.O.; funding acquisition, X.T. All authors have read and agreed to the published version of the manuscript.

Funding: This research was funded by the National Natural Science Foundation of China, 31971843, the Technology System of Modern Agricultural Industry in Guangdong, 2020KJ105, and the Guangzhou Science and Technology Project, 202103000075.

Informed Consent Statement: Not applicable.

Data Availability Statement: The data presented in this publication are available on request from the corresponding author.

Conflicts of Interest: The authors declare no conflict of interest.

\section{References}

1. Hu, C.; Shi, J.; Quan, S.; Cui, B.; Kleessen, S.; Nikoloski, Z.; Tohge, T.; Alexander, D.; Guo, L.; Lin, H.; et al. Metabolic variation between japonica and indica rice cultivars as revealed by nontargeted metabolomics. Sci. Rep. 2014, 4, 5067. [CrossRef] [PubMed]

2. Fitzgerald, M.A.; McCouch, S.R.; Hall, R.D. Not just a grain of rice: The quest for quality. Trends Plant Sci. 2009, 14, 133-139. [CrossRef]

3. McNally, K.L.; Childs, K.L.; Bohnert, R.; Davidson, R.M.; Zhao, K.; Ulat, V.J. Genomewide SNP variation reveals relationships among landraces and modern varieties of rice. Proc. Natl. Acad. Sci. USA 2009, 106, 12273-12278. [CrossRef]

4. Juliano, B.O. Amylose analysis in rice-A review. In Proceedings of the Workshop on Chemical Aspects of Rice Grain Quality; Department of Chemistry, International Rice Research Institute, Los Banos: Laguna, Philippines, 1979; pp. $251-260$.

5. Okpala, N.E.; Potcho, M.P.; An, T.; Ahator, S.D.; Duan, L.; Tang, X. Low temperature increased the biosynthesis of 2-AP, cooked rice elongation percentage and amylose content percentage in rice. J. Cereal Sci. 2020, 93, 102980. [CrossRef]

6. Biselli, C.; Cavalluzzo, D.; Perrini, R.; Gianinetti, A.; Bagnaresi, P.; Urso, S.; Orasen, G.; Desiderio, F.; Lupotto, E.; Cattivelli, L.; et al. Improvement of marker-based predictability of Apparent Amylose Content in japonica rice through GBSSI allele mining. Rice 2014, 7, 1. [CrossRef]

7. Luo, Y.; Zakaria, S.; Basyah, B.; Ma, T.; Li, Z.; Yang, J.; Yin, Z. Marker-asssisted breeding of Indonesia local rice variety Siputeh for semi-dwarf phonetype, good grain quality and disease resistance to bacterial blight. Rice 2014, 7, 33. [CrossRef]

8. Zhu, C.; Shen, W.; Zhao, H.; Wan, J. Advances in researches of the application of low-amylose content rice gene for breeding. Sci. Agric. Sin. 2003, 37, 157-162.

9. Feng, F.; Li, Y.; Qin, X.; Liao, Y.; Siddique, K.H.M. Changes in Rice Grain Quality of Indica and Japonica Type Varieties Released in China from 2000 to 2014. Front. Plant Sci. 2017, 8, 1863. [CrossRef] [PubMed]

10. Champagne, E.T.; Bett-Garber, K.L.; Fitzgerald, M.A.; Grimm, C.C.; Lea, J.; Ohtsubo, K.; Jongdee, S.; Xie, L.; Bassinello, P.Z.; Resurreccion, A.; et al. Important Sensory Properties Differentiating Premium Rice Varieties. Rice 2010, 3, 270-281. [CrossRef]

11. Umemoto, T.; Yano, M.; Satoh, H.; Shomura, A.; Nakamura, Y. Mapping of a gene responsible for the difference in amylopectin structure between japonica-type and indica-type rice varieties. Theor. Appl. Genet. 2002, 104, 1-8. [CrossRef] [PubMed] 
12. Kang, H.J.; Hwang, I.K.; Kim, K.S.; Choi, H.C. Comparison of the Physicochemical Properties and Ultrastructure of Japonica and Indica Rice Grains. J. Agric. Food Chem. 2006, 54, 4833-4838. [CrossRef]

13. Koutroubas, S.D.; Ntanos, D.A. Genotypic differences for grain yield and nitrogen utilization in Indica and Japonica rice under Mediterranean conditions. Field Crops Res. 2003, 83, 251-260. [CrossRef]

14. Ntanos, D.A.; Koutroubas, S.D. Dry matter and N accumulation and translocation for Indica and Japonica rice under Mediterranean conditions. Field Crops Res. 2002, 74, 93-101. [CrossRef]

15. Chen, J.; Ding, J.; Ouyang, Y.; Du, H.; Yang, J.; Cheng, K. A triallelic system of S5 is a major regulator of the reproductive barrier and compatibility of indica-japonica hybrids in rice. Proc. Natl. Acad. Sci. USA 2008, 105, 11436-11441. [CrossRef] [PubMed]

16. Mano, Y.; Kawaminami, K.; Kojima, M.; Ohnishi, M.; Ito, S. Comparative Composition of Brown Rice Lipids (Lipid Fractions) of Indica and Japonica Rices. Biosci. Biotechnol. Biochem. 1999, 63, 619-626. [CrossRef] [PubMed]

17. Yang, Y.; Zhu, K.; Xia, H.; Chen, L.; Chen, K. Comparative proteomic analysis of a indicand japonica rice varieties. Genet.Mol. Biol. 2014, 37, 652-661. [CrossRef] [PubMed]

18. Tian, R.; Jiang, G.H.; Shen, L.H.; Wang, L.Q.; He, Y.Q. Mapping quantitative trait loci underlying the cooking and eating quality of rice using a DH population. Mol. Breed. 2005, 15, 117-124. [CrossRef]

19. Okpala, N.E.; Mo, Z.; Duan, M.; Tang, X. The genetics and biosynthesis of 2-acetyl-1-pyrroline in fragrant rice. Plant Physiol. Biochem. 2019, 135, 272-276. [CrossRef] [PubMed]

20. Arikit, S.; Wanchana, S.; Khanthong, S.; Saensuk, C.; Thianthavon, T.; Vanavichit, A. QTL-seq identifies cooked grain elongation QTLs near soluble starch synthase and starch branching enzymes in rice (Oryza sativa L.). Sci. Rep. 2019, 9, 8323. [CrossRef]

21. Ge, X.J.; Xing, Y.Z.; Xu, C.G.; He, Y.Q. QTL analysis of cooked rice grain elongation, volume expansion, and water absorption using a recombinant inbred population. Plant Breed. 2008, 124, 121-126. [CrossRef]

22. Qiu, X.; Yang, J.; Zhang, F.; Niu, Y.; Zhao, X.; Shen, C.; Chen, K.; Teng, S.; Xu, J. Genetic dissection of rice appearance quality and cooked rice elongation by genome-wide association study. Crop J. 2021, in press. [CrossRef]

23. Ahn, S.N.; Bollich, C.N.; McClung, A.M.; Tanksley, S.D. RFLP analysis of genomic regions associated with cooked-kernel elongation in rice. Theor. Appl. Genet. 1993, 87, 27-32. [CrossRef] [PubMed]

24. Yajima, I.; Yanai, T.; Nakamura, M.; Sakakibara, H.; Habu, T. Volatile flavor components of cooked rice kaorimai (scented rice, O. sativa japonica). J. Agric. Biol. Chem. 1978, 43, 2425-2429.

25. Widjaja, R.; Craske, J.D.; Wootton, M. Comparative studies on volatile components of non-fragrant and fragrant rices. J. Sci. Food Agric. 1996, 70, 151-161. [CrossRef]

26. Buttery, R.G.; Ling, L.C.; Juliano, B.O. 2-Acetyl-1-pyrroline: An important aroma component of cooked rice. Chem. Ind. 1982, 2, 958-959.

27. Hinge, V.R.; Patil, H.B.; Nadaf, A.B. Aroma volatile analyses and 2AP characterization at various developmental stages in Basmati and Non-Basmati scented rice (Oryza sativa L.) cultivars. Rice 2016, 9, 38. [CrossRef] [PubMed]

28. Hashemi, F.S.G.; Rafii, M.Y.; Ismail, M.R.; Mohamed, M.T.M.; Rahimc, H.A.; Latif, M.A.; Aslani, F. The genetic and molecular origin of natural variation for the fragrance trait in an elite Malaysian aromatic rice through quantitative trait loci mapping using SSR and gene-based markers. Gene 2015, 555, 101-107. [CrossRef] [PubMed]

29. Bourgis, F.; Guyot, R.; Gherbi, H.; Tailliez, E.; Amabile, I.; Salse, J. Characterization of the major fragance gene from an aromatic japonica rice and analysis of its diversity in Asian cultivated rice. Theor. Appl. Genet. 2008, 117, 353-368. [CrossRef]

30. Huang, T.C.; Teng, C.S.; Chang, J.L.; Chuang, H.S.; Ho, C.T.; Wu, M.L. Biosynthetic mechanism of 2-acetyl-1-pyrroline and its relationship with $\Delta 1$-pyrroline-5-carboxylic acid and methylglyoxal in aromatic rice (Oryza sativa L.) callus. J. Agric. Food Chem. 2008, 56, 7399-7404. [CrossRef] [PubMed]

31. Lorieux, M.; Petrov, N.; Huang, N.; Guiderdoni, E.; Ghesquiere, A. Aroma in rice: Genetic analysis of a quantitative trait. Theor Appl. Genet. 1996, 93, 1145-1151. [CrossRef]

32. Bradbury, L.M.T.; Fitzgerald, T.L.; Henry, R.J.; Jin, Q.; Waters, D.L.E. The gene for fragrance in rice. Plant Biotechnol. J. 2005, 3, 363-370. [CrossRef] [PubMed]

33. Ahn, S.N.; Bollich, C.N.; Tanksley, S.D. RFLP tagging of a gene for aroma in rice. Theor. Appl. Genet. 1992, 84, 825-828. [CrossRef]

34. Fitzgerald, T.L.; Waters, D.L.E.; Henry, R.J. The effect of salt on betaine aldehyde dehydrogenase transcript levels and 2-acetyl-1pyrroline concentration in fragrant and non-fragrant rice (Oryza sativa). Plant Sci. 2008, 175, 539-546. [CrossRef]

35. Bradbury, L.; Gillies, S.; Brushett, D.; Waters, D.; Henry, R. Inactivation of an aminoaldehyde dehydrogenase is responsible for fragrance in rice. Plant Mol. Biol. 2008, 68, 439-449. [CrossRef]

36. He, Q.; Park, Y.J. Discovery of a novel fragrant allele and development of functional markers for fragrance in rice. Mol. Breed. 2015, 35, 217. [CrossRef]

37. Khush, G.S. Origin, dispersal, cultivation and variation of rice. Plant Mol. Biol. 1997, 35, 25-34. [CrossRef] [PubMed]

38. Jackson, S.A. Rice: The first crop genome. Rice 2016, 9, 14. [CrossRef] [PubMed]

39. Heuberger, A.L.; Lewis, M.R.; Chen, M.; Brick, M.A.; Leach, J.E.; Ryan, E.P. Metabolomic and Functional Genomic Analyses Reveal Varietal Differences in Bioactive Compounds of Cooked Rice. PLoS ONE 2010, 5, e12915. [CrossRef]

40. Perkins, S.E.; Alexander, L.V.; Nairn, J.R. Increasing frequency, intensity and duration of observed global heatwaves and warm spells. Geophys. Res. Lett. 2012, 39, 20714. [CrossRef] 
41. Russo Russo, S.; Dosio, A.; Graversen, R.G.; Sillmann, J.; Carrao, H.; Dunbar, M.B.; Singleton, A.; Montagna, P.; Barbola, P.; Vogt, J.V. Magnitude of extreme heat waves in present climate and their projection in a warming world. J. Geophys. Res. Atmos. 2014, 119, 12500-12512. [CrossRef]

42. Yin, X.; Kropff, M.J. The effect of temperature on leaf appearance in rice. Ann. Bot. 1996, 77, 215-221. [CrossRef]

43. Dillahunty, A.L.; Siebenmorgen, T.J.; Mauromoustakos, A. Effect of Temperature, Exposure Duration, and Moisture Content on Color and Viscosity of Rice. Cereal Chem. 2001, 78, 559-563. [CrossRef]

44. Lu, G.; Wu, F.; Wu, W.; Wang, H.; Zheng, X.; Zhang, Y. Rice LTG1 is involved in adaptive growth and fitness under low ambient temperature. Plant J. 2014, 78, 468-480. [CrossRef]

45. Jia, Q.; Lv, B.; Guo, M.; Luo, C.; Zheng, L.; Hsiang, T. Effect of rice growth stage, temperature, relative humidity and wetness duration on infection of rice panicles by Villosiclavavirens. Eur. J. Plant Pathol. 2015, 141, 15-25. [CrossRef]

46. Perdomo, J.A.; Conesa, M.A.; Medrano, H.; Ribas-Carbó, M.; Galmés, J. Effects of long-term individual and combined water and temperature stress on the growth of rice, wheat and maize: Relationship with morphological and physiological acclimation. Physiol. Plant. 2015, 155, 149-165. [CrossRef] [PubMed]

47. Yamori, W.; Sakata, N.; Suzuki, Y.; Shikanai, T.; Makino, A. Cyclic electron flow around photosystem I via chloroplast NAD(P)H dehydrogenase (NDH) complex performs a significant physiological role during photosynthesis and plant growth at low temperature in rice. Plant J. 2011, 68, 966-997. [CrossRef] [PubMed]

48. Bao, G.; Ashraf, U.; Wang, C.; He, L.; Wei, X.; Zheng, A.; Mo, Z.; Tang, X. Molecular basis for increased 2-acetyl-1-pyrroline contents under alternatewetting and drying (AWD) conditions in fragrant rice. Plant Physiol. Biochem. 2018, 133, 149-157. [CrossRef] [PubMed]

49. Xu, F.; Sun, C.; Huang, Y.; Chen, Y.; Tong, C.; Bao, J. QTL mapping for rice grain quality: A strategy to detect more QTLs within sub-populations. Mol. Breed. 2015, 35, 105. [CrossRef]

50. Chen, M.H.; Bergman, C.; Pinson, S.; Fjellstrom, R. Waxy gene haplotypes: Associations with apparent amylose content and the effect by the environment in an international rice germplasm collection. J. Cereal Sci. 2008, 47, 536-545. [CrossRef]

51. Larkin, P.D.; Park, W.D. Transcript accumulation and utilization of alternate and non-consensus splice sites in rice granule-bound starch synthase are temperature-sensitive and controlled by a single-nucleotide polymorphism. Plant Mol. Biol. 1999, 40, 719-727. [CrossRef] [PubMed]

52. Wang, Z.Y.; Wu, Z.L.; Xing, Y.Y.; Zheng, F.G.; Guo, X.L.; Zhang, W.G. Nucleotide sequence of rice waxy gene. Nucleic Acids Res. 1990, 18, 19. [CrossRef] [PubMed]

53. Wang, Z.Y.; Zheng, F.Q.; Shen, G.Z.; Gao, J.P.; Snustad, D.P.; Li, M.G. The amylose content in rice endosperm is related to the post-transcriptional regulation of the waxy gene. Plant J. 1995, 7, 613-622. [CrossRef] [PubMed]

54. Sano, Y. Differential regulation of Waxy gene expression in rice endosperm. Theor. Appl. Genet. 1984, 68, 467-473. [CrossRef] [PubMed]

55. Tang, S.; Zhang, H.; Liu, W.; Dou, Z.; Zhou, Q.; Chen, W.; Wang, S.; Ding, Y. Nitrogen fertilizer at heading stage effectively compensates for the deterioration of rice quality by affecting the starch-related properties under elevated temperatures. Food Chem. 2019, 277, 455-466. [CrossRef] [PubMed]

56. Huang, M.; Jiang, L.; Zou, Y.; Zhang, W. On-farm assessment of effect of low temperature at seedling stage on early-season rice quality. Field Crops Res. 2013, 141, 63-68. [CrossRef]

57. Chen, S.H.; Yang, Y.; Shi, W.W.; Ji, Q.; He, F.; Zhang, Z.D. Badh2, encoding betaine aldehyde dehydrogenase, inhibits the biosynthesis of 2-acetyl-1- pyrroline, a major component in rice fragrance. Plant Cell 2008, 20, 1850-1861. [CrossRef] [PubMed] 